\title{
Analisis Perbandingan Biaya Pengangkutan Peti Kemas Menggunakan Moda Truk, Kereta Api dan Kapal Provinsi Sulawesi Selatan
}

\author{
Rifkah Fitriah $^{1 *}$, Misliah Idrus ${ }^{1}$, Andi Sitti Chairunnisa ${ }^{1}$ \\ ${ }^{1}$ Departemen Teknik Perkapalan, Fakultas Teknik, Universitas Hasanuddin \\ Jl. Poros Malino Km. 6, Bontomarannu, Kabupaten Gowa, Sulawesi Selatan, 92171 \\ *Email: rifkahzulkifli@gmail.com
}

DOI: 10.25042/jpe.052018.12

\begin{abstract}
Abstrak
Penelitian ini bertujuan untuk menganalisis asal dan tujuan peti kemas di Sulawesi Selatan, membandingkan biaya yang digunakan untuk distribusi peti kemas menggunakan moda truk, kereta api dan kapal dan menganalisis jarak peralihan moda untuk truk, kereta api dan kapal di Sulawesi Selatan.Lokasi penelitian terletak di Provinsi Sulawesi Selatan dengan pengumpulan data primer melalui instansi terkait yaitu Dinas Perhubungan Makassar dan Perusahaan Pelayaran serta data sekunder dari studi pustaka terkait. Metode yang digunakan dalam penelitian ini adalah perhitungan biaya tetap dan biaya variabel masing-masing moda hingga mengeluarkan grafik peralihan moda. Hasil penelitian menunjukkan bahwa peralihan moda terjadi pada jarak $50 \mathrm{~km}$, pendistribusian peti kemas menggunakan truk dapat beralih menggunakan moda kereta api. Pada jarak $150 \mathrm{~km}$, pendistribusian peti kemas jalur darat menggunakan moda truk dapat beralih ke jalur laut menggunakan kapal. Sedangkan pada jarak $250 \mathrm{~km}$, pendistribusian peti kemas jalur darat menggunakan moda kereta api dapat beralih ke moda kapal.
\end{abstract}

\begin{abstract}
Cost Comparison Analysis of Container Transport Using Truck, Rail And Sea Transport Modes in South Sulawesi. This research purposed are: (1) to analyze the origin and destination of containers in South Sulawesi, (2) to compare the costs used for the distribution of containers using truck, rail and ship modes and (3) to analyze the distance of mode transition for truck, rail and ship in South Sulawesi.The research was conducted in South Sulawesi Province. The primary data were collected through related institution, Makassar Transportation Department and Shipping Company. The secondary data were collected from related literature study. The method used in this research is the calculation of fixed costs and variable costs of each mode to issue a transition graph of modes. The results show that the mode transition occurs at $50 \mathrm{~km}$ of distance, the distribution of containers using truck can switch using rail mode. At $150 \mathrm{~km}$ of distance, the distribution of containers using truck mode can switch to sea routes by ship. While at $250 \mathrm{~km}$ of distance, the distribution of container on land routes using rail mode can switch to ship mode.
\end{abstract}

Kata Kunci: Biaya pengangkutan peti kemas, peralihan moda, pendistribusian peti kemas

\section{Pendahuluan}

Sulawesi Selatan memiliki peranan yang sangat besar dalam perekonomian Pulau Sulawesi. Hal ini disebabkan karena salah satu pelabuhan utama yang menunjang pergerakan Pulau Sulawesi ini terletak di Kota Makassar yang merupakan ibukota dari provinsi Sulawesi Selatan. Pelabuhan Soekarno Hatta sebagai pelabuhan yang memegang peranan penting dalam mendukung aktivitas ekspor impor dan menunjang penguatan perekonomian dari Sulawesi. Namun, salah satu faktor yang menyebabkan belum optimalnya performa pelabuhan pada umumnya adalah kondisi infrastruktur dan suprastruktur pelabuhan yang tidak sebanding dengan demand yang tinggi sehingga dwelling time di pelabuhan menjadi sangat lama. Hal ini dapat dilihat pada realisasi arus barang dan kunjungan kapal di pelabuhan ini, dimana aktivitasnya khususnya peti kemas telah melampaui prediksi sesuai yang tercantum dari Rencana Induk Pelabuhan [1].

Manajemen PT Terminal Petikemas Makassar (TPM) menyampaikan bahwa adanya arus peti 
kemas 600 ribu Twenty-foot equivalent unit (TEUs) pada akhir tahun 2016. Angka ini tumbuh sekitar 10 persen dibandingkan angka sebelumnya sekitar 558 ribu TEUs pada tahun 2015. Data arus peti kemas dari tahun 2011 sampai dengan tahun 2015 dapat dilihat pada Tabel 1 berikut.

Tabel 1. Arus kunjungan peti kemas pelabuhan utama Soekarno-Hatta

\begin{tabular}{|c|c|c|c|c|c|c|c|}
\hline \multirow[b]{2}{*}{ CABANG } & \multirow[b]{2}{*}{ SATUAN } & \multicolumn{5}{|c|}{ REALISASI } & \multirow{2}{*}{$\begin{array}{c}\text { RATA-RATA } \\
\text { PERTUMBUHAN }\end{array}$} \\
\hline & & $\begin{array}{c}\text { TAHUN } \\
2011\end{array}$ & $\begin{array}{c}\text { TAHUN } \\
2012\end{array}$ & $\begin{array}{c}\text { TAHUN } \\
2013\end{array}$ & $\begin{array}{c}\text { TAHUN } \\
2014\end{array}$ & $\begin{array}{c}\text { TAHUN } \\
2015\end{array}$ & \\
\hline Terminal & Unit & 394.991 & 459.387 & 473.387 & 480.878 & 474.894 & $5 \%$ \\
\hline Petikemas & Teus & 450.567 & 529.316 & 550.916 & 562.046 & 558.957 & $6 \%$ \\
\hline Makassar & Ton & 7.107 .851 & 8.059 .389 & 8.474 .572 & 8.983 .350 & 8.300 .816 & $4 \%$ \\
\hline
\end{tabular}

(sumber: Pelindo IV)

Pelabuhan muatan petikemas pada terminal Sukarno-Hatta sebagai pelabuhan utama satusatunya merupakan asal dan tujuan muatan dalam kemasan petikemas ke seluruh wilayah di Sulawesi Selatan. Pendistribusian petikemas ini melalui moda transportasi darat dengan jaringan jalan terbatas, kapasitas jaringan terbatas, Jarak relatif jauh, dan kualitas fisik jalan rendah. Dampak pengangkutan petikemas jarak jauh dan berada di pusat kota Makassar dapat memicu kemacetan, meningkatkan kecelakaan di jalan raya, kurang efisien dan efektif karena biaya dan waktu pendistribusian menjadi besar, meningkatkan biaya pemeliharaan fisik jalan raya akibat frekuensi dan beban muatan truk yang mengangkut petikemas semakin meningkat.

Pembangunan rel kereta api trans Sulawesi merupakan salah satu upaya pemerintah Provinsi Sulawesi Selatan dan pemerintah pusat dalam mengatasi kemacetan dan untuk menghubungkan wilayah atau perkotaan yang mempunyai potensi angkutan penumpang dan barang atau komoditas berskala besar, berkecepatan tinggi, dengan tingkat konsumsi energi yang rendah dan mendukung perkembangan perkotaan terpadu melalui integrasi perkotaan di wilayah pesisir, baik industri maupun pariwisata serta agropolitan baik kehutanan, pertanian maupun perkebunan. Pembangunan rel ini sepanjang $2000 \mathrm{~km}$ dari Makassar-Manado dengan tahap pertama rute Makassar-Parepare sepanjang $144 \mathrm{~km}$. Jalur kereta api akan dibangun dengan lebar rel 1,435 mm dengan kecepatan maksimal mencapai $200 \mathrm{~km} / \mathrm{jam}$ [2].

Biaya merupakan faktor yang sangat menentukan dalam kegiatan transportasi dalam penetapan tarif, dan alat kontrol agar dalam pengoperasian mencapai tingkat yang seefisien dan seefektif mungkin. Beberapa biaya yang termasuk dalam biaya transportasi melilputi biaya modal (capital costs), biaya operasional (operational costs), biaya tetap (fixed cost) dan biaya variabel (variabel cost), biaya kendaraan (automobile cost), biaya gabungan (joint cost), biaya langsung (direct cost) dan biaya tidak langsung (indirect cost), biaya unit (unit cost), biaya rata-rata (average cost) dan biaya pelayanan (cost of service) [3].

Setiap moda memiliki biaya sendiri/kinerja, persaingan aktual antara moda tergantung jarak tempuh, muatan yang diangkut dan nilai barang. Seperti yang ditunjukkan dalam gambar 1, moda transportasi yang berbeda memiliki fungsi biaya yang berbeda. Jalan, kereta api dan transportasi laut memiliki masing-masing $\mathrm{C} 1, \mathrm{C} 2$ dan $\mathrm{C} 3$ biaya fungsi. Sementara jalan memiliki fungsi biaya lebih rendah untuk jarak pendek, fungsi biaya naik lebih cepat daripada fungsi biaya rel dan laut. Pada jarak D1, menjadi lebih menguntungkan untuk menggunakan transportasi kereta api daripada transportasi jalan sementara dari jarak D2, transportasi laut menjadi lebih menguntungkan. Titik D1 umumnya terletak antara 500 dan $750 \mathrm{~km}$ dari titik keberangkatan sementara D2 sekitar $1.500 \mathrm{~km}$ [4].

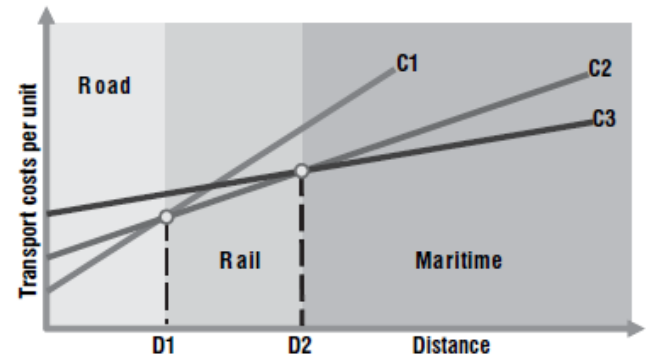

Gambar 1. Jarak, pilihan moda dan biaya transportasi 
Adapun tujuan penelitian ini adalah menganalisis asal dan tujuan peti kemas di Sulawesi Selatan, membandingkan biaya yang digunakan untuk distribusi peti kemas menggunakan moda truk, kereta api dan kapal dan menganalisis jarak peralihan moda untuk truk, kereta api dan kapal di Sulawesi Selatan.

Data yang dianalisis adalah sebagai berikut:

1. Mengidentifikasi : a) asal dan tujuan peti kemas yang dapat dilalui dengan moda darat dan laut di Sulawesi Selatan, b) kapasitas kendaraan darat dan laut yang digunakan.

2. Menghitung jumlah muatan peti kemas yang diangkut dan jumlah frekuensi pengangkutan yang dibutuhkan.

3. Menghitung biaya kendaraan darat dan laut yang terdiri atas biaya tetap dan biaya variabel. Biaya tetap merupakan fungsi dari kapasitas kendaraan dan biaya variabel merupakan fungsi dari jarak dan frekuensi.

4. Mengeluarkan grafik perpotongan peralihan moda truk, kereta api dan kapal.

\section{Pembahasan}

Di Provinsi Sulawesi Selatan kabupaten yang muatannya dapat didistribusikan melalui jalur darat dan laut ada 5 kabupaten yaitu Pangkep, Barru, Parepare, Bone dan yang paling terjauh adalah Palopo. Berdasarkan hasil analisa data Asosiasi Logistik Forwarding Indonesia, pergerakan peti kemas tertinggi ke wilayah Palopo dengan jumlah perminggunya dapat mencapai 600 box dengan jumlah harian 60 unit. Urutan kedua oleh Kotamadya Parepare dengan jumlah maksimum 255 box perminggunya [5].

Tabel 2. Jumlah maksimum distribusi peti kemas di beberapa wilayah kabupaten

\begin{tabular}{|c|c|c|c|}
\hline Daerah Tujuan & Ukuran & Waktu & Jumlah Perminggu \\
\hline \multirow{2}{*}{ Parepare } & $20 \mathrm{Ft}$ & \multirow{2}{*}{2 hari } & 175 box \\
\hline & $40 \mathrm{Ft}$ & & 80 box \\
\hline \multirow{2}{*}{ Palopo } & $20 \mathrm{Ft}$ & \multirow{2}{*}{3 hari } & 500 box \\
\hline & $40 \mathrm{Ft}$ & & 100 box \\
\hline \multirow{2}{*}{ Bone } & $20 \mathrm{Ft}$ & \multirow{2}{*}{3 hari } & 50 box \\
\hline & $40 \mathrm{Ft}$ & & 30 box \\
\hline \multirow{2}{*}{ Garongkong } & $20 \mathrm{Ft}$ & \multirow{2}{*}{2 hari } & 2 box \\
\hline & $40 \mathrm{Ft}$ & & 2 box \\
\hline
\end{tabular}

\subsection{Biaya Transportasi Kapal}

Kapal yang digunakan untuk mengangkut peti kemas dari pelabuhan asal Makassar ke pelabuhan tujuan Pangkep, Barru, Parepare, Bone dan Palopo digunakan kapal yang sama yaitu kapal KM Mentari Express 2993 GT. Berikut adalah rekapitulasi perhitungan biaya tetap dan biaya variabel untuk moda kapal. Rekapitulasi biaya kapal dapat dilihat pada Tabel 3 berikut.

Tabel 3. Rekapitulasi biaya kapal

\begin{tabular}{lrr}
\hline \multicolumn{1}{c}{ Uraian } & $\begin{array}{c}\text { Biaya } \\
\text { (Rp/Tahun) }\end{array}$ & $\begin{array}{c}\text { Biaya } \\
\text { (Rp/km ton) }\end{array}$ \\
\hline Biaya Tetap & & \\
\hline Biaya Penyusutan & $8,588,000,000$ & 547.34 \\
\hline Bunga Modal & $8,483,475,000$ & 540.68 \\
\hline Premi asuransi kapal & $3,390,000,000$ & 216.06 \\
\hline Biaya ABK & $1,716,000,000$ & 109.37 \\
\hline Biaya RMS & $6,780,000,000$ & 432.11 \\
\hline Biaya Gemuk & $2,280,000$ & 0.15 \\
\hline Jumlah & $\mathbf{2 8 , 9 5 9 , 7 5 5 , 0 0 0}$ & $\mathbf{1 , 8 4 5 . 7 0}$ \\
\hline Biaya Tidak Tetap & & \\
\hline Biaya BBM & $599,723,397$ & 35.67 \\
\hline Biaya Pelumas & $231,135,774$ & 14.73 \\
\hline Biaya Air Tawar & $30,909,081$ & 1.97 \\
\hline Biaya Pelabuhan Palopo & $158,630,328$ & 10.11 \\
\hline Biaya Pelabuhan & $123,289,204$ & 7.86 \\
Makassar & & $\mathbf{7 0 . 3 4}$ \\
\hline Jumlah & $\mathbf{8 2 1 , 7 6 8 , 2 5 2}$ & \\
\hline
\end{tabular}

\subsection{Biaya Transportasi Truk}

Jenis truk yang digunakan untuk pengangkutan peti kemas $20 \mathrm{ft}$ adalah truk merk HINO FL260JT dengan harga truk sebesar Rp 687.000.000. Frekuensi pengangkutan peti kemas dilakukan 30 kali dalam sebulan atau setiap hari. Berikut adalah tabel rekapitulasi perhitungan biaya tetap dan biaya variabel untuk moda truk. Rekapitulasi biaya truk dapat dilihat pada Tabel 4 berikut.

Tabel 4. Rekapitulasi biaya truk

\begin{tabular}{lrr}
\hline \multicolumn{1}{c}{ Uraian } & $\begin{array}{c}\text { Biaya } \\
\text { (Rp/Tahun) }\end{array}$ & $\begin{array}{c}\text { Biaya } \\
(\mathbf{R p} / \mathbf{k m} \text { ton })\end{array}$ \\
\hline Biaya Tetap & & \\
\hline Biaya Bunga Modal & $25,788,263$ & 8.62 \\
\hline Penyusunan & $9,457,040$ & 3.16 \\
\hline Perizinan & $3,150,000$ & 1.05 \\
\hline Asuransi & $9,618,000$ & 3.22 \\
\hline Uang Saku & $378,000,000$ & 126.36 \\
\hline Total Biaya Tetap & $\mathbf{4 2 6 , 0 1 3 , 3 0 3}$ & $\mathbf{1 4 2 . 4 1}$ \\
\hline Biaya Tidak Tetap & & \\
\hline BBM & $232,368,000$ & 77.68 \\
\hline Tol & $14,400,000$ & 4.81 \\
\hline Total Biaya Tidak Tetap & $\mathbf{2 4 6 , 7 6 8 , 0 0 0}$ & $\mathbf{8 2 . 4 9}$ \\
\hline
\end{tabular}




\subsection{Biaya Transportasi Kereta Api Barang}

Biaya investasi atau harga kereta api sebesar Rp. 29.000.000.000 referensi harga kereta api tersebut berdasarkan sumber data PT. KAI DAOP VII Madiun dimana kereta tersebut merupakan kereta buatan PT. INKA dengan masa pemakaian 30 tahun, dengan kapasitas 20 gerbong dan frekuensi 10 kali pengangkutan dalam sebulan. Rekapitulasi biaya kereta api dapat dilihat pada Tabel 5 berikut.

Tabel 5. Rekapitulasi biaya kereta api

\begin{tabular}{lrr}
\hline \multicolumn{1}{c}{ Uraian } & $\begin{array}{c}\text { Biaya } \\
\text { (Rp/Tahun) }\end{array}$ & $\begin{array}{c}\text { Biaya } \\
\text { (Rp/km ton) }\end{array}$ \\
\hline Biaya Tetap & & \\
\hline Biaya Bunga Modal & $2,550,235,613$ & 127.88 \\
\hline Biaya Penyusunan & $400,371,034$ & 20.08 \\
\hline Biaya Pegawai Awak & $131,224,860$ & 6.58 \\
Saran KAI & & \\
\hline Biaya Penggunaan Sarana & $96,000,000$ & 4.81 \\
\hline Asuransi & $435,000,000$ & 21.81 \\
\hline Prasarana milik PT KAI & $1,160,000,000$ & 58.17 \\
\hline Biaya Perawatan & $200,000,000$ & 10.03 \\
\hline Tunjangan Kerja Operasi & $224,859,000$ & 11.28 \\
Awak Sarana KAI & & \\
\hline Penelitian dan & 369,960 & 0.02 \\
Pengembangan Litbang & & 0.05 \\
\hline Pengembangan SDM & 986,760 & 1,58 \\
\hline On Training Cleaning & $31,590,000$ & 1,46 \\
\hline Cucian Sarana & $29,160,000$ & 2.56 \\
\hline Biaya Pemasaran & $51,000,000$ & $\mathbf{2 6 6 . 3 0}$ \\
\hline & $\mathbf{5 , 3 1 0 , 7 9 7 , 2 2 7}$ \\
\hline Biaya Tidak Tetap & & 68.89 \\
\hline BBM & $1,373,904,000$ & $\mathbf{6 9 . 6 9}$ \\
\hline Pelumas & $15,898,500$ & \\
\hline & $\mathbf{1 , 3 8 9 , 8 0 2 , 5 0 0}$ & \\
\hline
\end{tabular}

\subsection{Peralihan Moda Truk, Kereta Api dan Kapal}

Setelah mendapatkan biaya tetap dan variabel dalam ton $\mathrm{km}$ untuk setiap moda maka biaya tersebut dikalikan dengan jarak $0-400 \mathrm{~km}$. Biaya ton/km untuk masing-masing moda dapat dilihat pada tabel 6 berikut.

Tabel 6. Biaya/ton km masing-masing moda dikalikan jarak

\begin{tabular}{crrr}
\hline Jarak & $\begin{array}{c}\text { Biaya/ton } \\
\text { km Kapal }\end{array}$ & $\begin{array}{c}\text { Biaya/ton km } \\
\text { Truk }\end{array}$ & $\begin{array}{c}\text { Biaya/ton km } \\
\text { Kereta Api }\end{array}$ \\
\hline 0 & 1,846 & 16 & 266 \\
\hline 50 & 5,363 & 4,141 & 4,109 \\
\hline 100 & 8,880 & 8,265 & 7,953 \\
\hline 150 & 12,397 & 12,390 & 11,796 \\
\hline 200 & 15,914 & 16,514 & 15,639 \\
\hline 250 & 19,431 & 20,639 & 19,482 \\
\hline
\end{tabular}

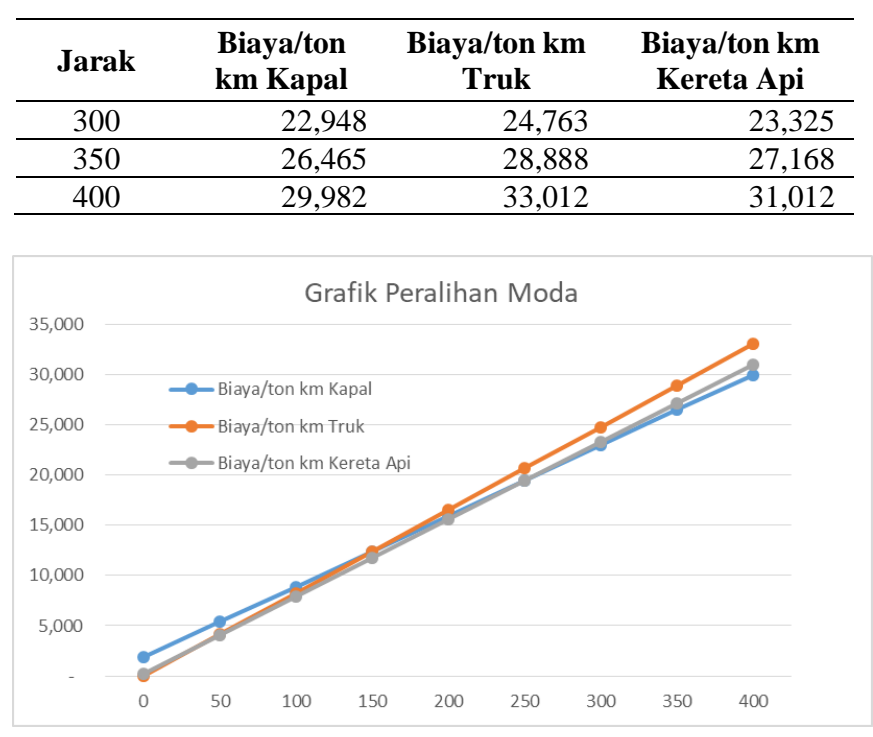

Gambar 2. Grafik peralihan moda

Peralihan moda pengangkutan peti kemas dari Makassar menuju kabupaten tujuan di Sulawesi Selatan berdasarkan grafik di atas adalah

1. Dengan jarak sekitar $50 \mathrm{~km}$, pengangkutan peti kemas menggunakan truk dapat beralih menggunakan moda kereta api.

2. Dengan jarak sekitar $150 \mathrm{~km}$, pengangkutan peti kemas menggunakan truk dapat beralih ke moda kapal.

3. Dengan jarak $250 \mathrm{~km}$, pengangkutan peti kemas menggunakan kereta api dapat beralih ke moda kapal.

Untuk melihat lebih jelas titik potong grafik biaya moda dengan jarak, maka grafik dipecah menjadi 3 bagian sebagai berikut.

\subsection{Peralihan Moda Truk dengan Kapal}

Tabel 7. Biaya/ton km moda kapal dan truk dikalikan jarak

\begin{tabular}{crr}
\hline Jarak & $\begin{array}{c}\text { Biaya/ton } \\
\text { km Kapal }\end{array}$ & $\begin{array}{c}\text { Biaya/ton km } \\
\text { Truk }\end{array}$ \\
\hline 0 & 1,846 & 16 \\
\hline 50 & 5,363 & 4,141 \\
\hline 100 & 8,880 & 8,265 \\
\hline 150 & 12,397 & 12,390 \\
\hline 200 & 15,914 & 16,514 \\
\hline 250 & 19,431 & 20,639 \\
\hline 300 & 22,948 & 24,763 \\
\hline 350 & 26,465 & 28,888 \\
\hline 400 & 29,982 & 33,012 \\
\hline
\end{tabular}




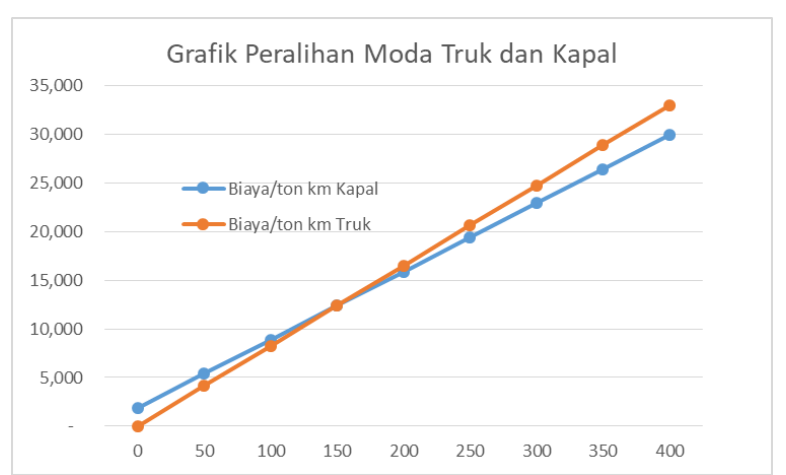

Gambar 3. Peralihan moda truk dengan kapal

Berdasarkan grafik di atas terlihat perpotongan grafik biaya dan jarak antara moda truk dan kapal pada jarak sekitar $150 \mathrm{~km}$. Hal ini menunjukkan peralihan moda dari truk ke kapal berada di titik $150 \mathrm{~km}$. Dengan kapasitas kapal 160 box peti kemas dalam satu kali perjalanan lebih menguntungkan memakai moda kapal dibandingkan dengan truk yang mengangkut peti kemas dengan kapasitas 1 box peti kemas tiap harinya.

\subsection{Peralihan Moda Kereta Api dengan Kapal}

Tabel 8. Biaya/ton km moda kapal dan kereta api dikalikan jarak

\begin{tabular}{crr}
\hline Jarak & $\begin{array}{c}\text { Biaya/ton } \\
\text { km Kapal }\end{array}$ & $\begin{array}{c}\text { Biaya/ton km } \\
\text { Kereta Api }\end{array}$ \\
\hline 0 & 1,846 & 266 \\
\hline 50 & 5,363 & 4,109 \\
\hline 100 & 8,880 & 7,953 \\
\hline 150 & 12,397 & 11,796 \\
\hline 200 & 15,914 & 15,639 \\
\hline 250 & 19,431 & 19,482 \\
\hline 300 & 22,948 & 23,325 \\
\hline 350 & 26,465 & 27,168 \\
\hline 400 & 29,982 & 31,012 \\
\hline
\end{tabular}

Grafik Peralihan Moda Kereta Api dan Kapal

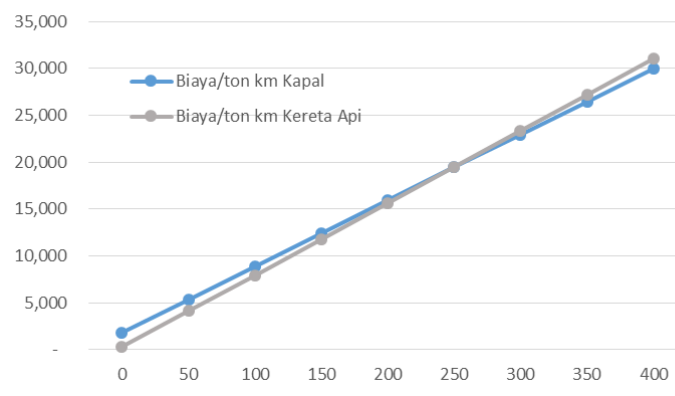

Gambar 4. Peralihan moda kereta api dengan kapal
Berdasarkan grafik di atas terlihat perpotongan grafik biaya dan jarak antara moda kereta api dan kapal pada jarak $250 \mathrm{~km}$. Hal ini menunjukkan peralihan moda dari kereta api ke kapal berada di titik 250 km. Dengan kapasitas kapal 160 box peti kemas dalam satu kali perjalanan lebih menguntungkan memakai moda kapal dibandingkan dengan kereta api yang mengangkut peti kemas dengan kapasitas 20 gerbong atau untuk 20 box peti kemas dalam sekali perjalanan.

\subsection{Peralihan Moda Truk dengan Kereta Api}

Tabel 9. Biaya/ton $\mathrm{km}$ moda truk dan kereta api dikalikan jarak

\begin{tabular}{crr}
\hline Jarak & $\begin{array}{c}\text { Biaya/ton km } \\
\text { Truk }\end{array}$ & $\begin{array}{c}\text { Biaya/ton km } \\
\text { Kereta Api }\end{array}$ \\
\hline 0 & 16 & 266 \\
\hline 50 & 4,141 & 4,109 \\
\hline 100 & 8,265 & 7,953 \\
\hline 150 & 12,390 & 11,796 \\
\hline 200 & 16,514 & 15,639 \\
\hline 250 & 20,639 & 19,482 \\
\hline 300 & 24,763 & 23,325 \\
\hline 350 & 28,888 & 27,168 \\
\hline 400 & 33,012 & 31,012 \\
\hline
\end{tabular}

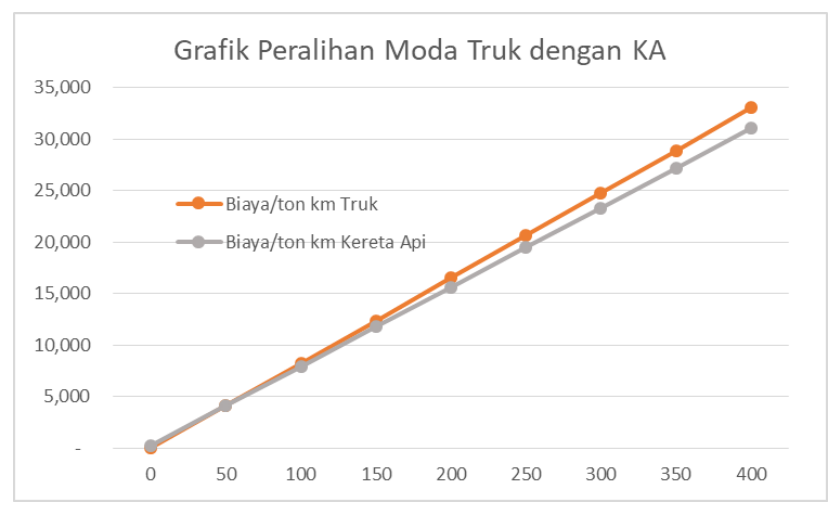

Gambar 5. Peralihan moda kereta api dengan kapal

Berdasarkan grafik di atas terlihat perpotongan grafik biaya dan jarak antara moda truk dan pada jarak sekitar $50 \mathrm{~km}$. Hal ini menunjukkan peralihan moda dari kereta api ke truk berada di titik $50 \mathrm{~km}$. Dengan kapasitas 20 gerbong atau untuk 20 box peti kemas dalam sekali perjalanan lebih menguntungkan pada jarak ini dibandingkan dengan menggunakan truk untuk mengangkut 1 box peti kemas dalam sekali perjalanan. 


\section{Kesimpulan}

Berdasarkan hasil penelitian yang telah dilakukan maka dapat ditarik kesimpulan sebagai berikut :

1. Pendistribusian peti kemas di Sulawesi Selatan dengan Makassar sebagai pelabuhan asal mempunyai 5 kabupaten tujuan pendistribusian yang dapat dilalui dengan jalur darat maupun laut yaitu Pangkep, Barru, Parepare, Bone dan yang paling terjauh adalah Palopo.

2. Peralihan moda terjadi pada jarak $50 \mathrm{~km}$, yaitu pendistribusian peti kemas menggunakan truk dapat beralih menggunakan moda kereta api. Pada jarak $150 \mathrm{~km}$, pendistribusian peti kemas jalur darat menggunakan moda truk dapat beralih ke jalur laut menggunakan kapal. Sedangkan pada jarak $250 \mathrm{~km}$, pendistribusian peti kemas jalur darat menggunakan moda kereta api dapat beralih ke moda kapal.

\section{Referensi}

[1] Apriani, Nini. 2015. Pengembangan Potensi Lokasi Penerapan Dry Port Dalam Wilayah Sulawesi Selatan. Program Pascasarjana Universitas Hasanuddin, Makassar.

[2] Dewa, Syarifuddin. 2015. Pengembangan Jaringan Distribusi Angkutan Peti Kemas di Sulawesi Selatan. Universitas Hasanuddin, Makassar.

[3] Suwandi, Arief. 2016. Biaya, Tarif Angkutan dan Pembentukan Harga.

[4] Rodrigue, Jean-Paul. 2006. The Geography of Transport Systems. Routledge, New York.

[5] Nurbaya. 2015. Peluang Pengangkutan Peti Kemas Melalui Laut dengan Pelabuhan Makassar Sebagai Pusat Distribusi. Program Pascasarjana Universitas Hasanuddin, Makassar. 